\title{
CRITERIOS PARA EL REFUERZO ANTISÍSMICO DE ESTRUCTURAS HISTÓRICAS
}

\author{
Fernando Peña Mondragón ${ }^{(1)}$ y Paulo B. Lourenço ${ }^{(2)}$
}

\begin{abstract}
RESUMEN
Los arquitectos y los ingenieros han utilizado una amplia variedad de técnicas de reparación o refuerzo para mejorar la respuesta estructural de estructuras históricas. Algunas de estas técnicas de intervención han sido específicamente implementadas para mejorar la capacidad de las estructuras antiguas para resistir terremotos. El uso de estas técnicas debe considerar tanto la acción sobre la estructura original como el modo en que afectan la integridad y la autenticidad de los materiales originales y las características estructurales. El propósito del presente trabajo es revisar los criterios actuales de refuerzo utilizados en la restauración de edificios históricos.
\end{abstract}

Palabras Clave: Estructuras históricas; técnicas de refuerzo; mampostería; criterios de refuerzo

\begin{abstract}
Architects and engineers have used a wide variety of repair or strengthening interventions to improve the structural response of ancient masonry structures. Some of these intervention techniques have been specifically implemented to upgrade the capacity of ancient structures to resist earthquakes. The use of these techniques must considerer the action on the original structure, and by the way they affect the integrity and the authenticity of the original materials and the structural features. The purpose of the present document is to review the actual criteria of the strengthening solutions used in restoration of historical structures.
\end{abstract}

Key Words: Historical structures; strengthening techniques; masonry; strengthening criteria

\section{INTRODUCCIÓN}

La preservación de las estructuras históricas no es una tarea sencilla, sobre todo cuando se debe proponer una intervención para mejorar su comportamiento sísmico. Esto se debe principalmente a que el criterio que se utilice debe reconocer explícitamente que la conservación del Patrimonio Arquitectónico se debe centrar en tres puntos fundamentales: la seguridad física de las personas, la salvaguarda de los valores intrínsecos del edificio (ver siguiente sección) y el uso, actual y futuro, que se le dé a la construcción.

Hasta mediados del siglo pasado se consideraba que la conservación de una estructura histórica se garantizaba mediante una gran intervención de restauración. Así mismo, se tenía una fe ciega en la

Artículo recibido el 7 de junio de 2011 y aprobado para su publicación el 20 de junio de 2012

1 Instituto de Ingeniería, Universidad Nacional Autónoma de México. Edificio 2, Circuito Escolar, Ciudad Universitaria, 04510, México, DF. fpem@pumas.iingen.unam.mx

2 ISISE, Departamento de Ingeniería Civil, Universidade do Minho, Azurém. P-4800-058, Guimarães, Portugal. pbl@civil.uminho.pt 
tecnología y materiales modernos de aquella época como el concreto y el acero; mientras que se despreciaban los materiales originales y las técnicas antiguas de construcción. No se reconocían claramente los valores intrínsecos de las estructuras, así como la importancia de estudios previos a la intervención (ICOMOS, 1931). Todo esto derivó en malas experiencias de restauración.

A partir de la Carta de Venecia (ICOMOS, 1964) se reconoce explícitamente la salvaguarda de los valores intrínsecos de la estructura. Por lo que la conservación se fundamenta en el conocimiento y el entendimiento global del comportamiento de la estructura y de las causas reales de los posibles daños y alteraciones. Se busca que la intervención sea mínima y respetuosa; así como se establece la importancia de que la intervención se fundamente en un método científico, mediante estudios previos. Los estudios que se realicen para proponer una rehabilitación deben ser multidisciplinarios y requieren de la cooperación de distintos profesionistas como historiadores, arquitectos, ingenieros, restauradores de arte, entre otros (ICOMOS, 2003a; Peña et al., 2010).

Por otro lado, existe una amplia gama de técnicas de refuerzo para mejorar la respuesta estructural de las construcciones históricas (EECCP, 2006b; Zegarra et al., 1997; Meli y Sánchez Ramírez, 2007; Paret et al., 2008; Borri et al., 2002). Sin embargo, hay que tener en mente que estas intervenciones siempre tienen una acción directa sobre la estructura original, sus materiales o elementos. Por lo que se puede afectar la integridad y la autenticidad de los materiales originales, así como las características estructurales del inmueble a intervenir. Esto puede también, modificar el comportamiento sísmico de la edificación, tanto de forma positiva como negativa (EECCP, 2006a).

Debido a esto, cada construcción se convierte en un problema único, con su propia identidad. Por lo que no se puede dar ninguna regla en general para valorar a priori la eficacia de una posible intervención. Así como tampoco se puede generalizar la eficiencia de una técnica para un problema en particular. En la práctica, cada una de las posibles soluciones se debe considerar con sumo cuidado y se debe valorar a detalle tanto su aplicabilidad, como sus pros y contras de cada problema en específico.

A pesar de esto, los criterios actuales de conservación no se encuentran difundidos correctamente en el ámbito de la práctica, por lo que desafortunadamente aún sigue siendo muy común las intervenciones inadecuadas en este tipo de edificaciones. Debido a esta falta de conocimiento, a menudo la componente histórica ha sido mutilada o destruida por los ingenieros y arquitectos que no reconocen este hecho, con la aprobación de las autoridades y de otros profesionistas implicados. Por otra parte, es frecuente que autoridades e ingenieros intenten aplicar los reglamentos de construcción desarrollados para edificaciones modernas, al momento de intervenir una estructura histórica, lo cual es generalmente inaceptable.

Así, la necesidad de la difusión de la información existente y de los criterios actuales de intervención es una demanda que se necesita satisfacer. De este modo, el objetivo de este trabajo es presentar los criterios generales que actualmente rigen a nivel mundial para plantear una intervención de refuerzo sísmico en estructuras históricas, así como también dar algunas recomendaciones generales.

\section{VALORES INTRÍNSECOS Y PRINCIPIOS DE CONSERVACIÓN DE ESTRUCTURAS HISTÓRICAS}

Debido a que el daño estructural de una edificación histórica tiene consecuencias no sólo a nivel de costos o pérdidas humanas, sino también a nivel cultural y patrimonial, el estudio de la seguridad estructural de este tipo de inmuebles es de vital importancia. Por lo tanto cuando se interviene una estructura histórica, la seguridad estructural que se debe cumplir va más allá de evitar fallas estructurales mayores y pérdidas de vidas. Se debe buscar, sobre todo, la salvaguarda de los valores intrínsecos del 
inmueble. Cuando hablamos de los valores intrínsecos de una estructura histórica nos referimos a todo aquello que se podría perder, sea tangible o intangible, en caso de la desaparición del inmueble histórico. Grosso modo podemos clasificarlos en cinco valores:

- Arquitectura. Además del estilo arquitectónico, la distribución de espacios, usos y modificaciones a lo largo de su historia forman parte del valor cultural del edificio histórico.

- Arte. El valor artístico reside tanto en su arquitectura, como en todos los demás elementos que le proporcionan una identidad al edificio, como pueden ser: frescos y pinturas murales, elementos de adorno (cielos rasos, adornos en columnas y muros, pisos, etc.), bienes muebles conservados en el interior del edificio, etc.

- Económico. Los edificios y centros históricos son, muchas veces, la atracción principal de una ciudad, creando beneficios económicos directos e indirectos.

- Historia. El valor cultural histórico de un inmueble no se refiere únicamente a la época en que fue construido, sino también a todos los hechos de que ha sido testigo mudo. Como por ejemplo, ser la casa en donde vivió cierto personaje de la historia, lugar donde se redactó o firmó cierto acuerdo, etc.

- Ingeniería. La concepción estructural de un edificio histórico forma también parte de su valor cultural. Ésta muestra en forma tangible las antiguas técnicas de construcción y los materiales usados. Las estructuras de los monumentos constituyen sin duda alguna un documento histórico y un legado vivo de las habilidades de los antiguos constructores.

Lamentablemente, muchas veces el ingeniero no reconoce o toma en cuenta estos valores para proponer el proyecto de intervención. Otras veces, se reconocen sólo algunos de ellos (como arte, historia y arquitectura), pero la falta de información sobre las técnicas y materiales de construcción de épocas pasadas hacen que el valor de la ingeniería se desprecie y se pierda o mutile al proponer una rehabilitación con técnicas modernas y novedosas.

La selección de una técnica de refuerzo debe estar basada en los principios de conservación y los criterios modernos para la intervención de estructuras históricas, los cuales se encuentran estipulados de forma general en la Carta de Venecia (ICOMOS, 1964) y de forma particular en los criterios ISCARSAH de ICOMOS (2003a). Estos principios incluyen los requisitos de diseño que en forma resumida son los siguientes:

- Respeto a la autenticidad estructural. La concepción estructural de los edificios históricos es parte de su valor cultural, por lo que es necesario preservar tanto el sistema original como sus materiales.

- Mínima alteración o impacto. Las intervenciones que causen la mínima alteración o impacto al sistema original deberían preferirse, siempre y cuando provean un nivel de seguridad adecuado.

- Seguridad estructural. En el caso de monumentos valiosos, las intervenciones deben considerar las pérdidas artísticas o culturales que el edificio puede experimentar en caso de daño estructural.

- Compatibilidad. Los materiales y los dispositivos técnicos utilizados para reparación o refuerzo deben ser compatibles con los originales, es decir, que su utilización no resulte en un efecto indeseable en la estructura. Los materiales antiguos no deberían experimentar algún tipo de deterioro químico cuando esté en contacto con los materiales nuevos (compatibilidad química), y los materiales nuevos no deberían experimentar fenómenos químicos o físicos que puedan causar algún daño a los materiales existentes.

- No sea invasor. Se deberían preferir las intervenciones que sean lo menos invasoras posibles, dado que esto contribuye a preservar la integridad de las estructuras (primer requisito). Entre varias alternativas, se debería dar preferencia a la que presente una invasión mínima. 
- Reversibilidad y remoción. Siempre que sea posible, las medidas adoptadas deben ser reversibles. Es decir, que al desmantelarlas, el material original o la estructura regresan al estado en que estaba antes, sin sufrir daño o deterioro permanente. Un requisito menos rígido es el de la remoción con deterioro limitado o duradero en la construcción original. La reversibilidad o remoción abre la posibilidad de reponer o cambiar, en el futuro, el refuerzo por otro más adecuado o efectivo.

- Monitorización. Debe ser posible controlar la intervención durante su ejecución. No se deberían permitir acciones que sean imposibles de controlar. Un programa de supervisión y control debería acompañar a cualquier propuesta de intervención, con el fin de evitar dañar a la estructura durante los trabajos de intervención.

a)

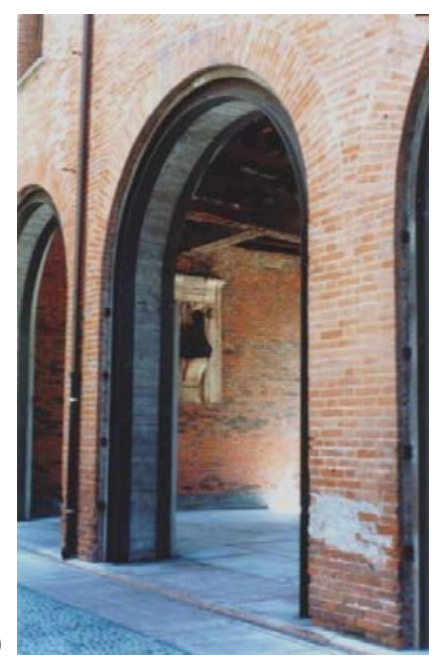

b)

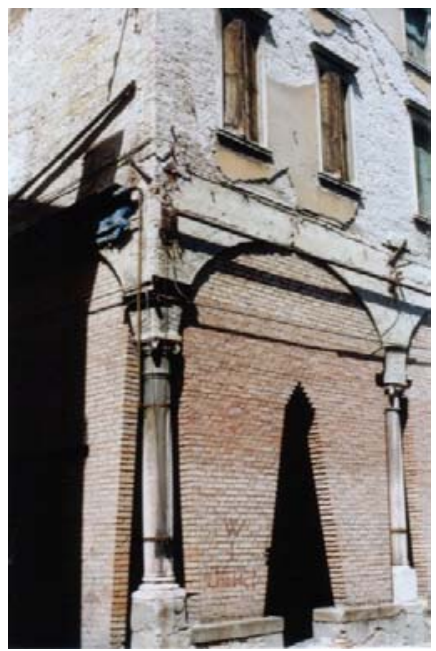

Figura 1. Ejemplos del principio de alteración: a) solución que altera poco el sistema original; b) solución que altera totalmente el sistema original

a)

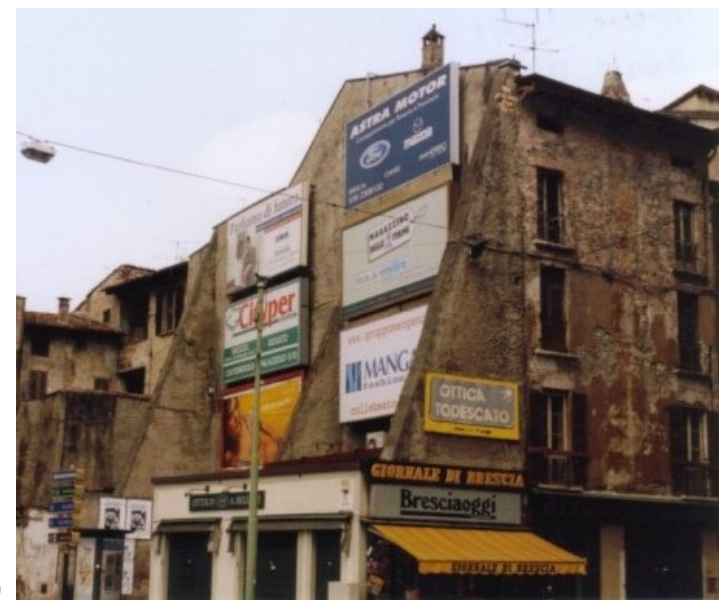

b)

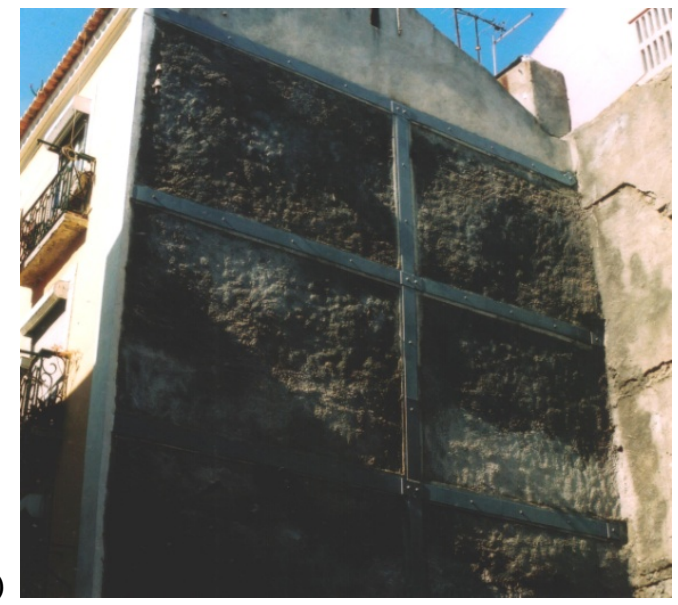

Figura 2. Ejemplos de soluciones poco invasoras: a) solución tradicional a base de contrafuertes; b) solución moderna a base de perfiles de acero

Como ejemplo de aplicación de estos criterios obsérvese la Figura 1 donde se muestra dos soluciones de refuerzo distintas para arcadas. La primera solución (Fig. 1a) es un refuerzo externo mediante encamisado de perfiles de acero y concreto. Aquí se trató de que la intervención fuera lo menos invasora posible y la estructura sufriera la mínima alteración. Por otro lado, la segunda solución (Fig. 1b) 
es un refuerzo externo mediante la colocación de un nuevo elemento de mampostería. Esta intervención de emergencia es invasora, altera la arquitectura del edificio y no respeta la estructura original. Sin embargo, es reversible y de fácil remoción permitiendo que al final de la intervención el edificio recupere su forma original.

Otro ejemplo se presenta en la Figura 2, donde se muestran dos tipos diferentes de intervención en caso de demolición parcial de la estructura. La primera (Fig. 2a) consistió en la colocación de contrafuertes que representan una mínima alteración en el sistema original. Sin embargo, la colocación de locales comerciales en la base de los contrafuertes, así como de publicidad, alteran el estilo arquitectónico del inmueble; lo cual es una falta de respeto a los valores intrínsecos de la estructura. La segunda (Fig. 2b) es una intervención moderna que incluye la colocación de perfiles de acero. Aquí se observa que la intervención es lo menos invasora posible, ya que el acero se colocó en las zonas críticas de la estructura.

Un ejemplo de compatibilidad entre materiales se presenta en la Figura 3. La Figura 3a presenta una intervención con el fin de crear una cochera en una casa histórica de adobe. Aquí no se respetan los valores intrínsecos de arquitectura ni ingeniería al no respetar los espacios originales y cambiar el sistema estructural. Además, no existe compatibilidad química entre el concreto y el adobe. Obsérvese el inicio de problemas de sulfatación en la base del muro de adobe. Así mismo se hace notar que este tipo de intervención es no reversible. Por otro lado, la Figura 3b muestra la reconstrucción de los capiteles de las columnas de unas ruinas romanas, en la ciudad de Mérida, España, utilizando el mismo tipo de piedra. En este caso en particular, se utilizaron vigas de concreto armado para restringir la parte superior de las columnas al darles continuidad con el resto de la estructura. Así mismo, se regresa en parte a la concepción original de la estructura.

a)

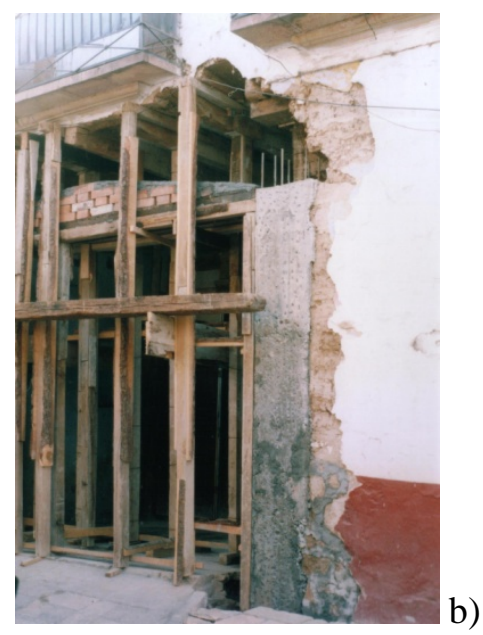

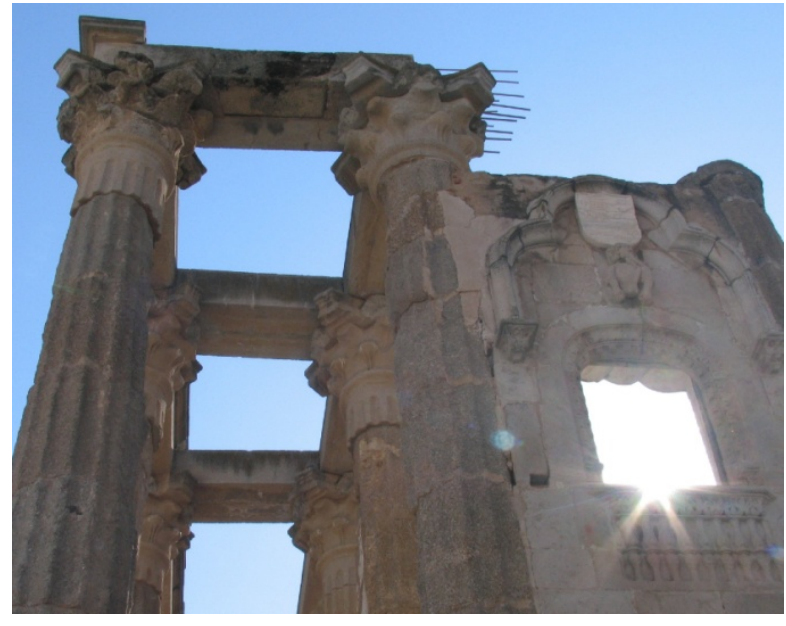

Figura 3. Ejemplos de compatibilidad de materiales: a) solución poco compatible; b) solución compatible

\section{METODOLOGÍA PARA LA INTERVENCIÓN ESTRUCTURAL}

La intervención estructural de edificios históricos es y debe ser multidisciplinario, en el cual intervienen disciplinas aparentemente desligadas entre sí: Arqueología, Arquitectura, Historia, Ingeniería, Restauradores de Arte, etc. Sin embargo, cuando un ingeniero se enfrenta a un trabajo de esta índole, generalmente se interrelaciona únicamente con el arquitecto quien es el que le marca las pautas a seguir. Lamentablemente, esta falta de integración provoca que, algunas veces, el proyecto estructural no se apegue a los lineamientos básicos de la conservación de edificios históricos (Peña et al., 2010). 
De este modo, la Ingeniería de la Conservación reconoce explícitamente el carácter multidisciplinario de la conservación y sobre todo, la importancia de conservar el valor intrínseco del patrimonio arquitectónico. Sin embargo, "el valor y la autenticidad del patrimonio arquitectónico no pueden fundamentarse en criterios predeterminados porque el respeto que merecen todas las culturas requiere que el patrimonio material de cada una de ellas sea considerado dentro del contexto cultural al que pertenecen” (ICOMOS, 2003a).

La combinación del conocimiento científico y cultural con la experiencia es indispensable para el estudio del patrimonio arquitectónico. El objetivo final de cualquier estudio, investigación e intervención debe ser la salvaguarda de los valores intrínsecos del edificio. De este modo, la Ingeniería de la Conservación es el medio científico con el cual se logra este resultado (Lourenço, 2006).

De acuerdo con las recomendaciones ISCARSAH de ICOMOS (2003b) un trabajo de intervención del patrimonio arquitectónico se puede dividir en cuatro aspectos principales que son (Fig. 4):

- Adquisición de datos

- Comportamiento estructural

- Diagnóstico y seguridad

- Medidas de intervención

La aplicación de esta metodología requiere un proceso iterativo entre la adquisición de datos, el estudio del comportamiento estructural, el diagnóstico y la evaluación de la seguridad de la estructura (Fig. 4). Las medidas de intervención estarán basadas en el diagnóstico y en la evaluación de la seguridad. Por lo tanto, el desarrollo incorrecto de estos pasos llevará a una conclusión inadecuada, que en algunos casos puede llegar a la destrucción total del valor intrínseco del inmueble (Lourenço, 2006).

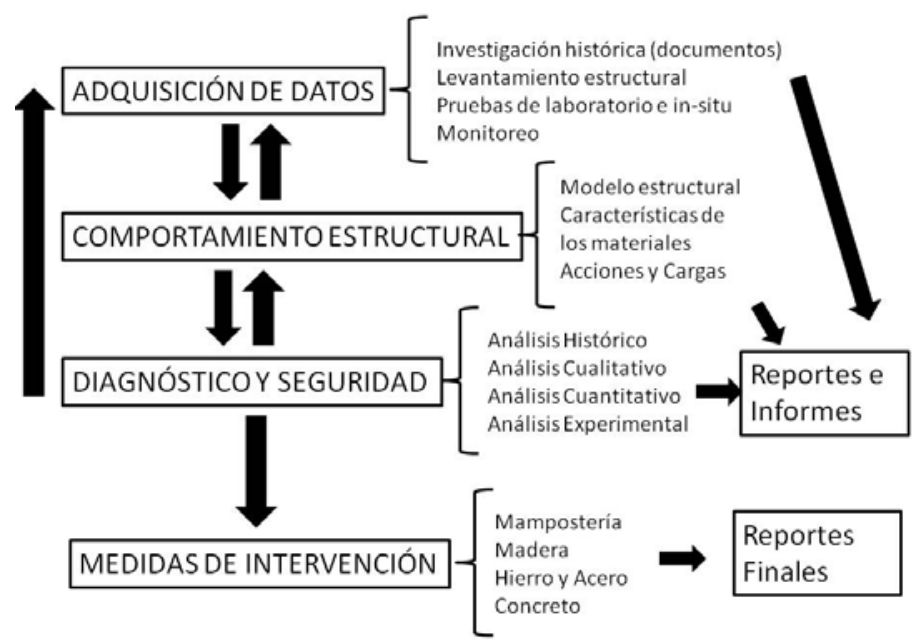

Figura 4. Diagrama de flujo con la metodología propuesta por ICOMOS para las intervenciones estructurales de edificios históricos (Lourenço, 2006)

\section{Adquisición de datos}

Para tener un buen entendimiento del comportamiento estructural, así como para hacer un diagnóstico adecuado, es necesario contar con toda la información disponible de la estructura. La 
información que se necesita recopilar debe incluir, entre otros: información histórica, materiales, descripción geométrica y estructural, estudios preliminares. La información histórica es de suma importancia pues ella nos permitirá entender el comportamiento estructural del edificio histórico a lo largo del tiempo, principalmente ante eventos extraordinarios como son: sismos, hundimientos diferenciales, huracanes, etc. De especial interés es la descripción histórica de los daños presentados, así como de las distintas reparaciones a las que ha sido sometido, como por ejemplo: cambios de materiales, modificaciones estructurales y arquitectónicas, cambios de uso y por lo tanto de cargas, entre otros (Peña et al., 2010).

En general, la geometría estructural de las construcciones históricas es bastante compleja, por lo que muchas veces se confunden los elementos arquitectónicos con los estructurales. Debido a esto es importante contar con una buena descripción geométrica y estructural. Cuando sea posible se recomienda la realización de estudios preliminares, fundamentalmente pruebas no destructivas o semi-destructivas realizadas in-situ, que ayuden a la caracterización de los materiales y detección de daño. Estas técnicas al no dañar la estructura, los elementos o los materiales son de gran utilidad en el estudio de las edificaciones históricas y se pueden dividir en: sónicas, de radar, termografía, vibración ambiental, gatos planos, entre otras (Binda et al., 2007; Bosiljkov et al., 2010; Gentile y Gallino, 2008). Estas técnicas dan una buena información sobre el estado de la estructura, sin embargo el equipo que utilizan es bastante costoso y se requiere de personal calificado para la interpretación de los resultados.

\section{Comportamiento estructural}

Los modelos numéricos permiten conocer el comportamiento estructural de los edificios históricos. Sin embargo, debido a las características particulares de estos edificios y de los materiales que los conforman, la modelación de estas estructuras no es una tarea fácil (Orduña et al., 2007). Así mismo, se hace necesario el uso de análisis inelásticos, especialmente en el estudio del comportamiento sísmico.

El Método de los Elementos Finitos ha mostrado ser una poderosa herramienta de análisis. Sin embargo, la cantidad de elementos necesarios para modelar adecuadamente una estructura histórica hacen que muchas veces el análisis dinámico no lineal sea en muchos casos difícil de llevar a cabo, por la gran demanda de recursos computacionales que requieren. Por tanto, los métodos simplificados de análisis han mostrado ser de gran eficacia para el análisis de este tipo de estructuras.

Actualmente existe una nueva estrategia de análisis llamado "Enfoque Integrado de Análisis Complementarios” (Peña, 2010). En la cual, la utilización de dos o más herramientas de análisis permite superar la complejidad en el estudio del comportamiento sísmico de estructuras antiguas de mampostería. De este modo, se utilizan los resultados obtenidos a partir de una herramienta de análisis como resultados preliminares o para una mejor concepción de otro modelo utilizando una herramienta de análisis diferente. Por otra parte, al unir los resultados de los diferentes modelos es posible obtener una mejor y más completa interpretación del comportamiento estructural.

\section{Diagnóstico y seguridad}

El proyecto de conservación debe estar basado en el entendimiento total de la estructura; es decir en el conocimiento de su comportamiento estructural, historia de su construcción y mantenimiento, tipología arquitectónica, cambios y daños sufridos a lo largo del tiempo, etc. De este modo, el diagnóstico y evaluación de la seguridad deben estar sustentados en información histórica, así como en procedimientos cualitativos y cuantitativos. Los procedimientos cualitativos se basan en la observación directa del daño estructural y de la degradación de los materiales, así como de una investigación histórica. Los 
procedimientos cuantitativos se basan principalmente en pruebas realizadas a los materiales y a la estructura en general, monitoreo y análisis estructural (ICOMOS, 2003a).

De este modo, el ingeniero se debe apoyar en otras disciplinas aparentemente desligadas con la suya, como la Historia y la Arquitectura. Así mismo, el análisis y modelado numérico se subordina a un estudio más completo de la estructura. Por lo que la evaluación de la seguridad estructural de un edificio histórico no debe estar basada únicamente en cálculos numéricos (estudio cuantitativo); sino también en las evidencias sobre el comportamiento del edificio ante eventos pasados (estudio cualitativo), es decir, con base en su propia historia.

\section{Medidas de intervención}

Las medidas de intervención deben estar basadas en las causas y atacar el problema de raíz y no remediar únicamente los síntomas. Así, cada intervención debe estar en proporción a los criterios de seguridad, manteniendo la intervención al mínimo posible para garantizar la seguridad y durabilidad de la estructura con el mínimo daño posible a los valores intrínsecos (ICOMOS, 2003a). Por lo tanto, no se pueden generalizar las ventajas o inconvenientes entre el uso de las técnicas "tradicionales" o "modernas" (ver siguiente Sección) de intervención, sino cada caso es diferente y por tanto el uso de cada técnica cambiará de acuerdo con la estructura. Sin embargo, es recomendable que cada intervención sea lo menos invasora y lo más compatible posible con sus valores intrínsecos, así como deben tomarse en cuenta también la durabilidad de la intervención y su grado de mejoramiento de la seguridad de la estructura.

Los modelos numéricos realizados para el estudio del comportamiento estructural, al estar ya calibrados y validados, se pueden utilizar para verificar la eficacia de las técnicas de refuerzo propuestas (Betti y Vignoli, 2008). Así mismo, en caso de estructuras de alta importancia y valor (histórico, artístico, cultural, económico, patrimonial), se pueden realizar pruebas de laboratorio en modelos a escala para verificar la viabilidad de las técnicas propuestas (Chávez y Meli, 2010).

Así mismo, se deben estudiar las características de los materiales usados en la restauración, en particular los materiales "nuevos o modernos", para garantizar la completa compatibilidad de ellos con los materiales originales de la construcción histórica. En especial se deben estudiar los efectos a largo plazo.

\section{SELECCIÓN DE LAS TÉCNICAS DE REFUERZO}

La selección de una técnica de refuerzo debe estar basada en los principios de conservación y los criterios modernos para el análisis y restauración de estructuras históricas (ICOMOS, 2003a,b). Cabe hacer notar que, cualquier técnica de refuerzo produce normalmente alguna pérdida del valor cultural, puesto que implica un cierto cambio en los materiales y elementos originales. Debido a esto, cada técnica se debe juzgar con base en su posible costo (pérdida del valor intrínseco) y beneficio (incremento de la vida útil, aumento en su capacidad sísmica, reducción de la probabilidad del daño parcial o total tanto de la estructura como de su contenido artístico). Por lo que es responsabilidad del profesionista encargado elegir la solución que proporcione la mejor relación costo - beneficio (Lourenço et al., 2007).

Así mismo, la selección de la técnica de refuerzo dependerá de la forma en que se quiera mejorar el comportamiento sísmico del edificio histórico. El comportamiento sísmico de una estructura se puede mejorar si se reduce la demanda sísmica, si se aumenta su capacidad o mediante una combinación de ambas acciones (EECCP, 2006a,b). 


\section{Reducción de la demanda sísmica}

La demanda sísmica se puede reducir por medio de:

- Modificar el periodo natural para obtener una menor amplificación de la aceleración del suelo. Esto conlleva un cambio (aumento, supresión o redistribución) en la masa o rigidez de la estructura. Estos cambios modificarán las propiedades dinámicas, principalmente el periodo natural de vibración, lo que permitiría mejorar su comportamiento sísmico. Sin embargo, hay que tener cuidado con esta técnica, pues se corre el riesgo de modificar irremediablemente los valores arquitectónicos e históricos del edificio.

- Mejorar las características del suelo o aislar la estructura del movimiento del suelo. Para la conservación de los valores intrínsecos estas podrían ser las mejores soluciones, pues su modificación ocurre a nivel de suelo y cimentación. Sin embargo, no todos los suelos son propicios para un mejoramiento sísmico. Por otro lado, el uso de aisladores puede ser una buena solución para edificios que no sean muy esbeltos para evitar que tengan problema de volteo, que se encuentren en terreno firme pues es en estos suelos donde el aislamiento es efectivo debido a las altas frecuencias dominantes del terreno. Así mismo, es necesario dejar una holgura alrededor de todo el perímetro del edificio y que la cimentación sea adecuada para insertar los aisladores y la estructura de transmisión de carga (Meli, 1998). Por lo que esta técnica no se puede aplicar a todos los edificios históricos.

- Cambiar el uso de la estructura. Con el cambio de uso se estarían modificando las cargas gravitacionales y la masa de la estructura. También se podría modificar la estructura (espacios, rigidez, resistencias) para cumplir con los nuevos requerimientos de uso. Sin embargo, se podría requerir una intervención mayor, que en muchos casos no sería necesaria o sería imposible de llevar a cabo.

\section{Aumento de la capacidad sísmica}

La capacidad sísmica de la estructura se puede aumentar al reforzar los elementos estructurales existentes y/o añadiendo elementos estructurales nuevos. Existen diversos criterios para clasificar las técnicas de refuerzo, uno de los más comunes y que aquí se utilizará es el de dividir las técnicas de refuerzo en tradicionales y modernas. Las técnicas tradicionales son aquellas que han sido aplicadas con métodos y materiales similares a los originales y que han sido utilizadas en el pasado. Las técnicas modernas son aquellas que utilizan materiales y dispositivos que se utilizan generalmente en la construcción actual o reparación de edificios nuevos.

Las principales desventajas que presentan las técnicas modernas es que no se tiene, en algunos casos, la experiencia suficiente para validar la efectividad, durabilidad y compatibilidad con la estructura y materiales originales. Por lo que, estas técnicas se deberían utilizar cuando los procedimientos tradicionales no sean aplicables o no proporcionen el nivel de refuerzo sísmico deseado. Sin embargo, el uso de cualquier técnica de refuerzo (tanto histórica como moderna) necesita ser acompañada de un estudio detallado sobre los posibles efectos en la estructura y materiales originales. Las Tablas 1 y 2 muestran una recopilación de algunas técnicas de refuerzo tradicionales y modernas, respectivamente, tomadas del reporte EECCP (2006b) en donde se explican en detalle estas técnicas.

De acuerdo con el reporte EECCP (2006b), las técnicas de refuerzo que se describen en las Tablas 1 y 2 constituyen intervenciones generales que se utilizan comúnmente en la práctica. Sin embargo, debe quedar claro que el que se hayan utilizado no quiere decir que sean las soluciones más adecuadas o efectivas para un problema en particular. Así como tampoco quiere decir, que estas técnicas cumplen con 
todos los principios y criterios de restauración. De hecho, muchas de las técnicas comúnmente utilizadas en la práctica se contraponen a los principios de conservación. Esto se debe al gran cambio que producen en los materiales originales, en la estructura o porque son irreversibles o son ampliamente invasoras. Por lo tanto, el diseñador debe analizar cuidadosamente las soluciones propuestas, tomando en cuenta la "unicidad" del problema a resolver, como son: las características de la estructura, la naturaleza de los problemas estructurales o del material que la afectan, el propósito de la intervención, su valor intrínseco, etc. Así mismo, el diseñador debe hacer un estudio crítico sobre la aplicabilidad de las soluciones propuestas y escoger así la mejor opción posible. La cual debe estar acorde con los principios generales de restauración.

Tabla 1. Técnicas tradicionales de refuerzo (EECCP, 2006b)

\begin{tabular}{|c|c|}
\hline Técnica & Descripción \\
\hline $\begin{array}{l}\text { Conexiones } \\
\text { locales }\end{array}$ & $\begin{array}{l}\text { Esta técnica permite, de modo sencillo, dar continuidad a diversas partes de la estructura } \\
\text { mediante el uso de diferentes dispositivos, como por ejemplo grapas. }\end{array}$ \\
\hline $\begin{array}{l}\text { Confinamiento } \\
\text { de columnas y } \\
\text { muros }\end{array}$ & $\begin{array}{l}\text { El confinamiento de elementos permite incrementar su capacidad para resistir } \\
\text { compresión, su capacidad de deformación e incrementar su rigidez. Esta técnica } \\
\text { incrementa la capacidad del elemento, pero tiene poca influencia en la capacidad global } \\
\text { de la estructura. El confinamiento de columnas se da principalmente con placas de acero } \\
\text { colocadas en las zonas críticas del elemento. Mientras que el confinamiento de muros se } \\
\text { hace, principalmente, mediante barras de acero inoxidable colocadas transversalmente. }\end{array}$ \\
\hline Contrafuertes & $\begin{array}{l}\text { La colocación de contrafuertes en las zonas críticas de la estructura ayuda a incrementar } \\
\text { la capacidad lateral de la estructura. El papel que juega este tipo de elementos consiste } \\
\text { en impedir los mecanismos de falla relacionados con las deformaciones laterales, al } \\
\text { tomar parte de las fuerzas horizontales. }\end{array}$ \\
\hline $\begin{array}{l}\text { Reconstrucción } \\
\text { local }\end{array}$ & $\begin{array}{l}\text { La mampostería dañada es retirada y reemplazada por mampostería nueva que tenga } \\
\text { propiedades mecánicas similares a la original. Esta técnica contribuye a preservar las } \\
\text { propiedades mecánicas originales y a dar continuidad a la estructura. Esta técnica puede } \\
\text { considerarse parcialmente reversible. }\end{array}$ \\
\hline Rejunteo & $\begin{array}{l}\text { Consiste en remover el mortero dañado y degradado de las juntas y sustituirlo con } \\
\text { mortero nuevo que cumpla con las características de compatibilidad (preferentemente } \\
\text { con mejores propiedades mecánicas) y durabilidad. Esta técnica se puede considerar } \\
\text { como parcialmente reversible. }\end{array}$ \\
\hline $\begin{array}{l}\text { Substitución de } \\
\text { elementos }\end{array}$ & $\begin{array}{l}\text { Esto es la substitución completa de un elemento estructural. Los materiales y } \\
\text { tecnologías utilizadas deben ser similares a los originales o si se utilizan soluciones } \\
\text { alternativas (modernas) deben de cumplir con los requisitos de diseño. El objetivo } \\
\text { principal de esta técnica es que el elemento recupere tanto su función original como la } \\
\text { corrección de algunos defectos. Un ejemplo típico es la sustitución de pisos y techos. }\end{array}$ \\
\hline Tensores & $\begin{array}{l}\text { Los tensores son barras o cables de acero que trabajan a tensión y se encuentran } \\
\text { anclados a la estructura mediante placas u otros dispositivos. Tienen diferentes } \\
\text { aplicaciones pero todas tienen la función de dar estabilidad o continuidad entre } \\
\text { diferentes partes de la estructura, por lo que son usados para mejorar el comportamiento } \\
\text { global del edificio. Esta técnica no es invasora y puede ser fácilmente removida. }\end{array}$ \\
\hline
\end{tabular}


Tabla 2. Técnicas modernas de refuerzo (EECCP, 2006b)

\begin{tabular}{|c|c|}
\hline Técnica & Descripción \\
\hline Anclajes & $\begin{array}{l}\text { El anclaje de un elemento, mediante barras o cables de acero, ayuda a mejorar la } \\
\text { estabilidad de la estructura o impedir deformaciones excesivas. }\end{array}$ \\
\hline $\begin{array}{l}\text { Costuras } \\
\text { armadas }\end{array}$ & $\begin{array}{l}\text { Esta técnica se basa en la realización de oquedades en los elementos a reforzar, en } \\
\text { donde se introducen barras de metal (acero inoxidable, titanio, etc.), las cuales son } \\
\text { después inyectadas, generalmente con mortero. Esta técnica no es muy recomendable, } \\
\text { debido a que es altamente invasora y no es reversible. }\end{array}$ \\
\hline $\begin{array}{l}\text { Encamisados } \\
\text { de concreto }\end{array}$ & $\begin{array}{l}\text { En caso de que un elemento presente altos niveles de esfuerzos de compresión, una } \\
\text { excesiva deformación lateral o se requiera mejorar la continuidad de los elementos, se } \\
\text { puede construir una estructura de concreto armado que recubra al elemento original. Se } \\
\text { ha observado que para obtener un trabajo eficiente de los elementos de concreto, éstos } \\
\text { se deben colocar a ambos lados del muro, así como que tengan una buena conexión } \\
\text { entre ellos mediante la distribución de varios conectores. Esta técnica se recomienda } \\
\text { principalmente para reforzar cimentaciones, ya que es altamente invasora, pues al } \\
\text { recubrir el elemento original se pierde parte de la identidad arquitectónica del inmueble. } \\
\text { Obviamente, esta técnica no se puede aplicar cuando el elemento contenga pinturas } \\
\text { murales u otro tipo de adorno arquitectónico o artístico. }\end{array}$ \\
\hline Inyección & $\begin{array}{l}\text { El objetivo de esta técnica consiste en inyectar mortero o resinas epóxicas a través de } \\
\text { grietas o agujeros previamente realizados, para rellenar las cavidades y vacíos al interior } \\
\text { de los elementos tratados; así como para rellenar grietas. Esto permite mejorar las } \\
\text { características mecánicas del material. Sin embargo, esta técnica no es reversible y } \\
\text { debería realizarse con materiales que hayan mostrado su compatibilidad con los } \\
\text { materiales originales, como el mortero de cal y arena. Cabe recordar que no se debe } \\
\text { utilizar esta técnica cuando el elemento presente frescos u otro tipo de pintura mural, } \\
\text { pues el material de inyección puede llegar a dañarlos irremediablemente. }\end{array}$ \\
\hline $\begin{array}{c}\text { Refuerzo } \\
\text { externo }\end{array}$ & $\begin{array}{l}\text { La aplicación de refuerzo en las caras externas de los elementos utilizando material de } \\
\text { alto rendimiento (como son las FRP, mallas de acero, polímeros, etc.) permite } \\
\text { incrementar su capacidad. Este refuerzo se une con el elemento original mediante } \\
\text { resinas epóxicas, morteros o pegamentos. Para que este tipo de refuerzo tenga un buen } \\
\text { rendimiento es necesario que la superficie en la que se aplique sea regular. Sin embargo } \\
\text { esta técnica no es reversible y obviamente no se puede aplicar en superficies que deban } \\
\text { ser conservadas en su forma original (pinturas murales, frescos, adornos, etc.). }\end{array}$ \\
\hline
\end{tabular}

\section{SELECCIÓN DE LOS MATERIALES}

Naturalmente, los materiales que se usen en las intervenciones deben respetar los principios de restauración presentados anteriormente. En forma particular el de durabilidad y compatibilidad (tanto química, como física y mecánica) con los materiales originales. Debido a que los materiales tradicionales (como por ejemplo los morteros de cal y arena) han mostrado ya su compatibilidad con los materiales históricos (morteros, piedras, tabiques, madera) se recomienda su uso sobre los materiales modernos en los que su durabilidad y compatibilidad todavía no ha sido verificada (Penelis, 2002). Al respecto, Liu et al. (2011) han demostrado que los materiales tradicionales no solo presentan una buena compatibilidad, sino también reducen el deterioro de las características mecánicas de los materiales históricos a lo largo del tiempo.

Los materiales modernos (como pueden ser el concreto, el acero, las resinas, verbigracia) han presentado, en algunos casos, problemas de durabilidad y compatibilidad. Por ejemplo, el acero de hierro 
y carbono llega a presentar corrosión fácilmente, lo que puede llevar a la pérdida de su capacidad de refuerzo. Además, hay que tener en cuenta que cuando el elemento de acero se corroe, éste se expande lo que puede generar agrietamiento severo o incluso la destrucción del material histórico. Obviamente, para las intervenciones en que sea necesario la utilización de acero de refuerzo se recomienda que éste sea inoxidable (ECCPP, 2006a). Recientemente se ha comenzado a hacer un mayor uso de otros metales de mayor durabilidad y compatibilidad, como el titanio, debido a que su costo se ha reducido. Un ejemplo es el caso de la Acrópolis en Atenas, donde se han usado barras de titanio para el refuerzo de las arquitrabes (Ganniari-Papageorgiou, 2009).

Las intervenciones en donde se ha usado concreto y mortero de cemento portland han mostrado problemas significativos de compatibilidad cuando se encuentran estos materiales en contacto directo con mamposterías históricas de piedra o tabique (Calderini, 2008). Estos problemas de compatibilidad abarcan tanto fenómenos químicos (por ejemplo la contaminación de la piedra original o tabique con sales solubles contenidas en el cemento Portland cuya cristalización es expansiva) como fenómenos mecánicos (incompatibilidad de deformaciones). Los cuales producen deterioro significativo en los componentes originales de mampostería (EECCP, 2006a, ver Figura 3a). En caso de que se necesite el uso de cemento en las mezclas, se recomienda que éste sea de tipo puzolánico pues ha mostrado una mejor compatibilidad que el portland. Sin embargo, como una recomendación más general, se desaconseja el uso de elementos de concreto pues generalmente se utilizan para cambiar la concepción original del sistema estructural para que ésta trabaje como una estructura moderna. Lo cual no se apega con los lineamientos internacionales de conservación, ni se respetan los valores intrínsecos de la estructura, en especial el de ingeniería.

De acuerdo con el reporte EECCPP (2006a), las resinas epóxicas han presentado, en muchos casos, problemas de durabilidad bastante significativos debido a una preparación o aplicación inadecuada. Las resinas epóxicas han causado también problemas de compatibilidad cuando son utilizadas en inyecciones, debido a que reducen significativamente la permeabilidad y transpiración natural de los materiales originales y presentan cambios de coloración, ya que se amarillenta con el tiempo. Algunos otros materiales modernos, como los Polímeros de Fibras Reforzadas (FRP), se presentan como aplicaciones eficientes, altamente versátiles y económicamente viables. Diversos estudios, tanto analíticos como experimentales, han mostrado la eficacia de estos sistemas (Corradi et al., 2007; Quagliarini et al., 2006). Sin embargo, su principal inconveniente es que no existen estudios del comportamiento de estos materiales a largo plazo, pues su utilización es relativamente reciente. Debido a esto, se recomienda cautela al utilizar estos materiales, principalmente, en estructuras de alto valor.

Una amenaza severa y que se debe tomar en cuenta al seleccionar los materiales en las intervenciones es la degradación y envejecimiento de los materiales causados por la intemperie. Esta problemática se ha agravado notablemente en los últimos años por la contaminación atmosférica (Fig. 5). El ataque químico a la piedra, los morteros y demás materiales y elementos constructivos básicos acelera notablemente su degradación, por lo que hay que considerarla al proponer una intervención. Uno de los factores que incrementan el ataque químico a los materiales es el excremento de las aves (palomas, gaviotas, cigüeñas, etc.). Por lo que es necesario evitar que éstas hagan nido en las construcciones históricas.

En la mayoría de los casos, la simple sustitución de los elementos (lo cual se conoce como “Anastilosis”) corrige esta problemática. Sin embargo, en otros casos debidos al valor histórico, arquitectónico o artístico de los materiales o del elemento la anastilosis no es una solución aceptable (Fig. 6). Para tales casos es necesario que un especialista en ciencia de materiales realice un proyecto de intervención. 
a)

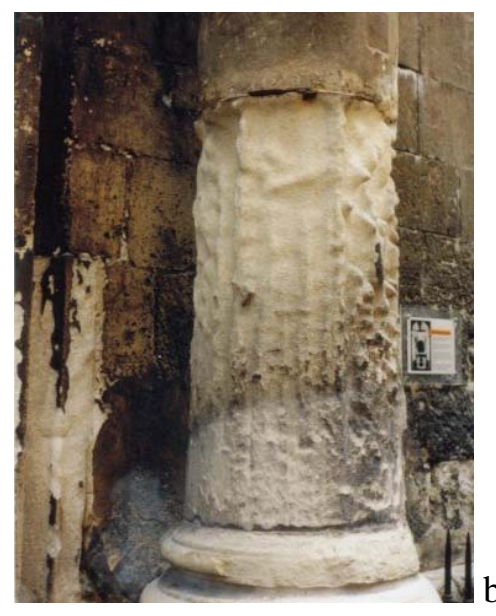

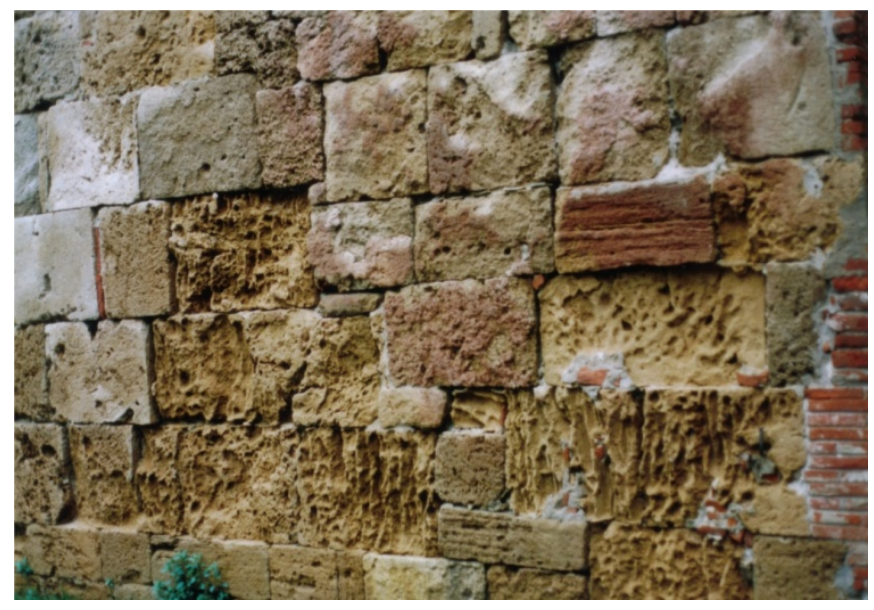

)

Figura 5. Deterioro de materiales por ataque atmosférico: a) bloque en fuste de columna; b) sillares de un muro de mampostería

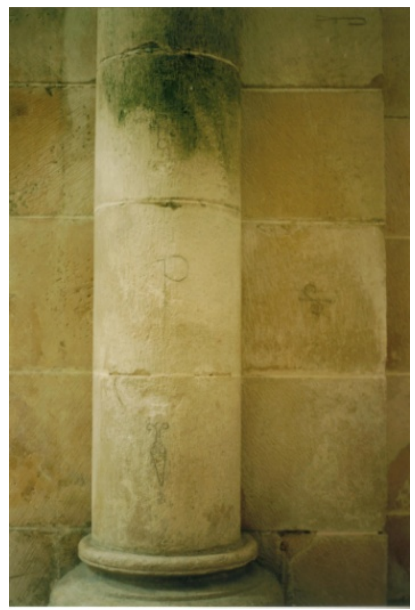

Figura 6. Bloques de piedra de una pilastra dañada por humedad y ataque de hongos, pero que no se pueden sustituir por el valor histórico y artístico del material (grabados en piedra)

\section{DOCUMENTACIÓN}

Uno de los requerimientos de la metodología de intervención es la realización de reportes e informes a lo largo del tiempo que duran los trabajos, con la finalidad de que sirvan de referencia para futuros proyectos de intervención (ver Fig. 4). Esto conlleva a que se cree una gran cantidad de información, la cual es generada por los distintos especialistas que intervienen en el proceso. Generalmente, esta información no es manejada adecuadamente, lo que provoca que en muchos casos se pierda a lo largo del tiempo. Por lo tanto, cuando se realiza el estudio histórico para una nueva intervención, éste queda incompleto o no se tiene la información de intervenciones pasadas. Es curioso que muchas veces la información histórica sea más fácil de encontrar que la información de intervenciones realizadas unos pocos años antes.

Así el concepto de documentación no se refiere únicamente al hecho de generar información a lo largo del proyecto de intervención, sino se refiere también a su correcto almacenamiento y diseminación. Debido a esto, la documentación es un reto para los diferentes especialistas que intervienen en un proyecto 
de restauración (Lourenço et al., 2011). De este modo, es responsabilidad de los profesionistas involucrados en el proceso de intervención, el de documentar adecuadamente el proyecto de intervención.

La carta de Venecia (ICOMOS, 1964), en su artículo 16, considera la necesidad de tener registros de cada etapa de los trabajos de intervención (limpieza, consolidación, refuerzo, verbigracia, Fig. 7). Así mismo, recomienda la publicación, preservación y disponibilidad de esta información. En este contexto, las recomendaciones ISCARSAH (ICOMOS, 2003) plantean la necesidad de registrar la información para facilitar la toma de decisiones, así como para la evaluación de la seguridad sísmica de la estructura. De este modo, la información histórica, el estado presente de la estructura, toda la información recopilada para el proyecto, el diagnóstico, la evaluación de la seguridad y la intervención debe ser registrada y documentada en una serie de reportes, los cuales deben contener (ICOMOS, 1996):

- El tipo, forma, dimensiones y características, externas e internas, del edificio.

- Los valores intrínsecos de la estructura.

- La tecnología y materiales usados durante su construcción y durante cualquier intervención relevante.

- La historia de los orígenes del edificio, incluyendo la fecha de construcción, arquitectos, dueños, diseño original, decoración, uso, entre otros.

- La historia del edificio a lo largo del tiempo, como los diferentes usos, eventos históricos, alteraciones a la estructura y estilo arquitectónico.

- La historia de las intervenciones (mantenimiento, reparaciones, rehabilitaciones, refuerzos, etc.); así como de la valoración de la condición actual del edificio, incluyendo los riesgos de carácter natural o antropogénico.

a)
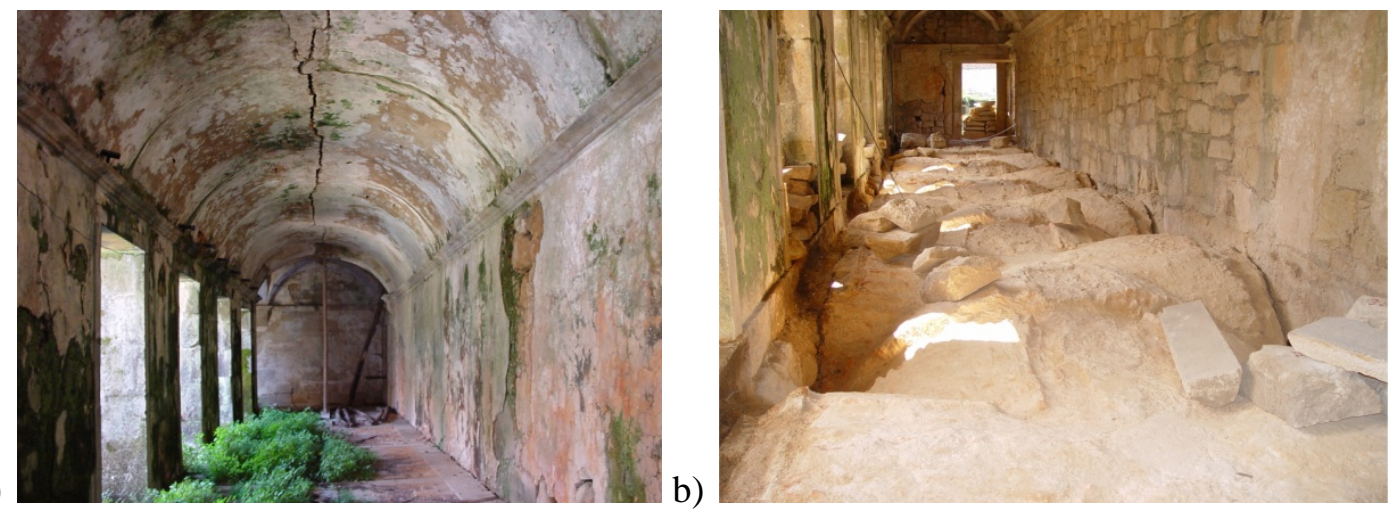

c)

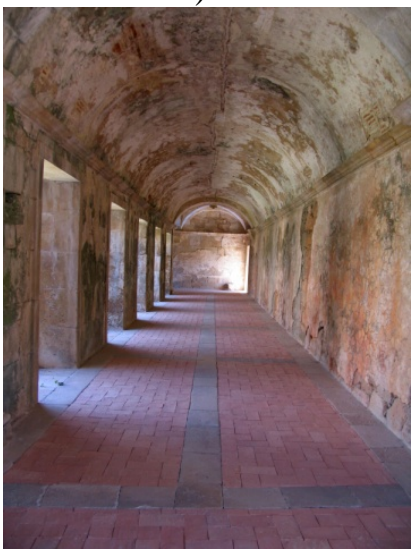

Figura 7. Refuerzo de las bóvedas de un claustro: a) estado original de una bóveda de cañón; b) estado de una bóveda de nervaduras durante la intervención; c) estado final de la bóveda de cañón 
Debido a la gran cantidad de información que se produce y que es requerida para el reporte final, es prácticamente imposible tener o publicar un solo documento. Por lo tanto, se vuelve indispensable el correcto manejo de los diferentes materiales. En este contexto, la carta de principios de documentación de ICOMOS (1996) da una serie de recomendaciones para un manejo adecuado de la información; los cuales de forma resumida son:

- Nivel de registro y diseminación. Dependiendo de a quién va dirigida la información, será el nivel de registro y documentación. Es decir, no es lo mismo crear un registro para el público en general, que para los profesionistas involucrados, que para investigación, administración o dependencias gubernamentales.

- Responsabilidad. La responsabilidad de conservar y mantener el patrimonio arquitectónico, así como todo lo que esto involucra, como la documentación, se debe establecer entre los propietarios, los especialistas, el gobierno y los usuarios. Por responsabilidad se entiende el requerir los reportes de la intervención, su correcto manejo, diseminación y preservación a lo largo del tiempo, así como su facilidad de acceso.

- Planeación. La documentación requiere un preciso y correcto plan que debe incluir el nivel y objetivo del registro, el medio de acceso a la información, su conservación y preservación a lo largo del tiempo, entre otros aspectos.

- Contenidos. Cada reporte y registro se debe realizar de forma normalizada. Entre los datos que deben siempre incluir es un número de identificación, la fuente de donde se obtuvo o quien lo creó. Así mismo, se debería crear una base de datos y un índice, para su fácil acceso.

- Estabilidad. Los materiales y técnicas usadas para la documentación y almacenamiento deben garantizar su estabilidad y durabilidad a lo largo del tiempo.

\section{ALGUNOS BREVES EJEMPLOS DE INTERVENCIONES}

En esta sección se presentan una serie de ejemplos prácticos, donde se han utilizado algunas de las técnicas descritas anteriormente, con la finalidad de que sirvan de referencia a la teoría aquí presentada.

La Figura 8 muestra la reconstrucción local de una bóveda. Nótese el uso de piedra del mismo tipo, así como la disposición de mangueras para una posterior inyección, con el fin de rellenar posibles vacíos. En este caso, se usó un mortero con cemento puzolánico. Por otro lado, la Figura 9 muestra el ejemplo de confinamiento de columnas mediante zunchos, para incrementar su capacidad de carga. Otra posible intervención podría ser la inyección de grietas del capitel y sustitución del fuste de la columna.

La Figura 10 muestra la restauración de un antiguo claustro, en la ciudad de Mérida, España, en las que se han utilizado diversas técnicas de refuerzo. Parte de los muros del piso superior se han reconstruido con mampostería de ladrillo y se ha reconstruido también parte de los arcos (reconstrucción local), se ha sustituido la pilastra del piso inferior (sustitución de elementos) y se han colocado soleras para dar continuidad a la pilastra adosada al muro (conexiones locales). Si bien es cierto que desde un punto de vista técnico estas soluciones pudieran ser las adecuadas, desde un punto de vista de la conservación de los valores intrínsecos de la estructura no son del todo apropiadas, pues no siguen los principios de conservación y requisitos de diseño. Esto conlleva a la pérdida de valores históricos, arquitectónicos e ingenieriles. 


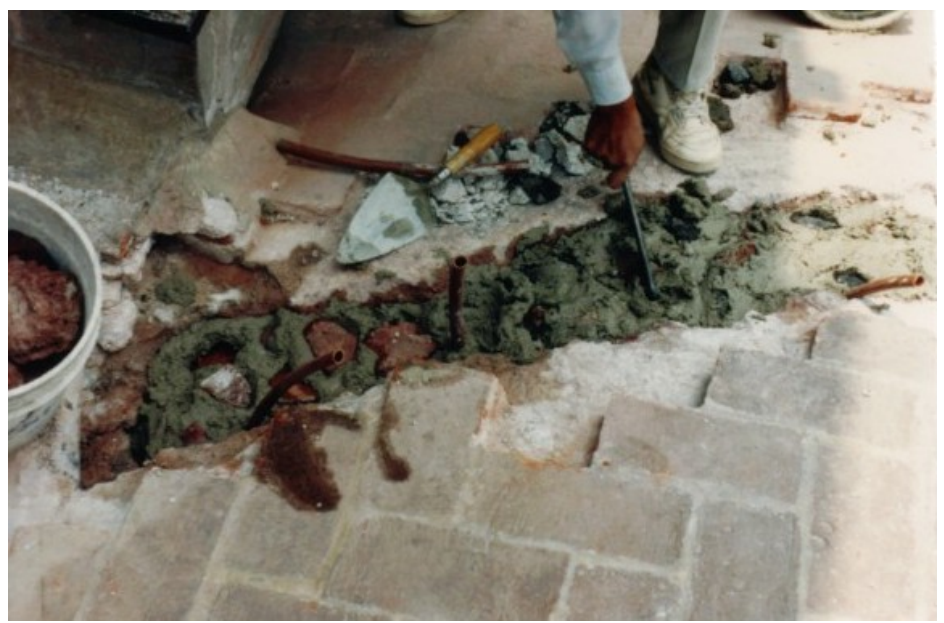

Figura 8. Reconstrucción local de una bóveda de la Catedral de la ciudad de México

a)
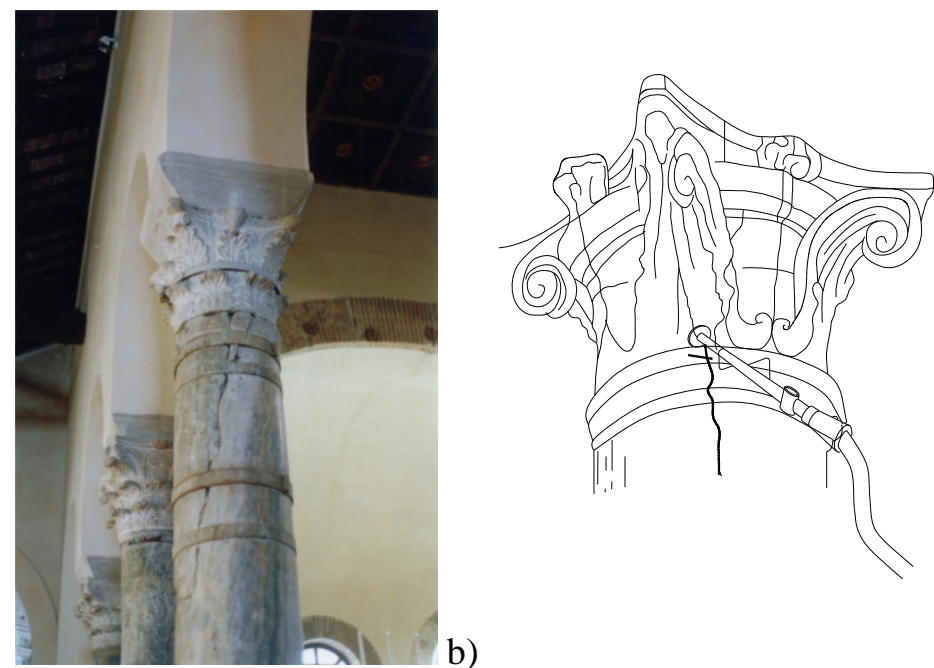

Figura 9. Refuerzo de una columna en la iglesia del Espíritu Santo, Ravena, Italia: a) mediante zunchos; b) mediante inyecciones

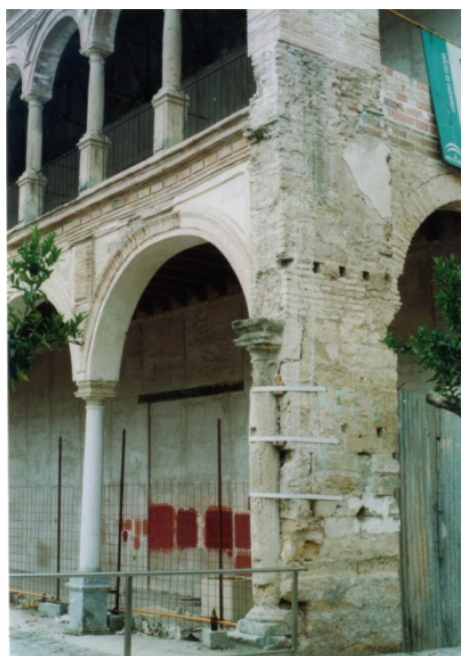

Figura 10. Intervención en un antiguo claustro en Mérida, España 


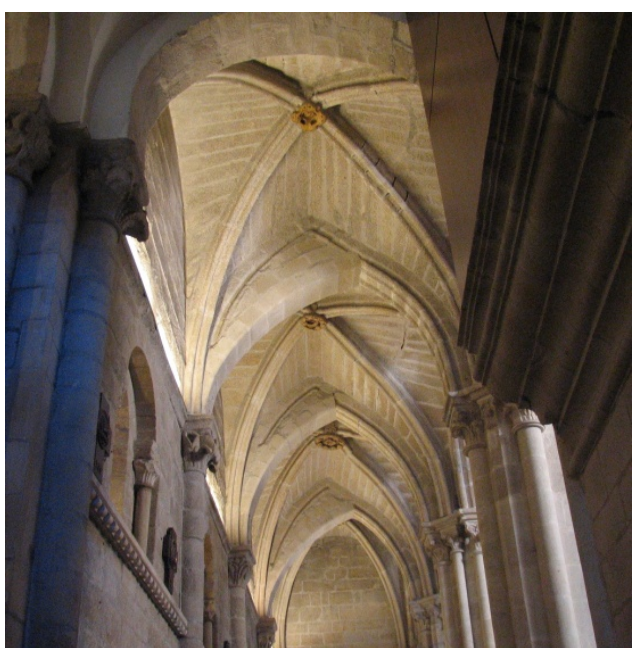

Figura 11. Refuerzo de arcos mediante la inclusión de elementos nuevos

Por otra parte, la Figura 11 presenta el refuerzo de una serie de arcos góticos, de la Catedral de Tuy en España, mediante la inclusión de un elemento nuevo. Se aprecia cómo los arcos han tenido una deformación importante, lo que ponía en riesgo la estabilidad de la bóveda. Debido a esto, se agregaron "medios" arcos nuevos con la finalidad de retomar la geometría inicial de la arcada, para aumentar la capacidad de la bóveda. Obsérvese que se utilizó material similar al original para tener una correcta compatibilidad entre los elementos nuevos y originales, así como para evitar una rigidización excesiva del arco. De este modo, se conserva la integridad arquitectónica e ingenieril de la estructura.

Un ejemplo típico de falta de integración entre el proyecto estructural y los lineamientos internacionales de conservación se muestra en la Figura 12. En esta iglesia del pueblo de Dolores Hidalgo, México, se cambió la cubierta original de bóveda de cañón por una techumbre más ligera de acero. Desde el punto de vista técnico, la intervención consistió en disminuir la masa de la estructura al cambiar el sistema de techo. Sin embargo, claramente no se respetaron los principios de conservación, pues la intervención modificó irremediablemente el sistema original, así como se perdieron los valores arquitectónico, histórico, artístico e ingenieril. Del mismo modo, la intervención no fue correcta desde un punto de vista funcional, pues se observa que la altura libre que quedó en el coro, después de la intervención, no permite su uso.

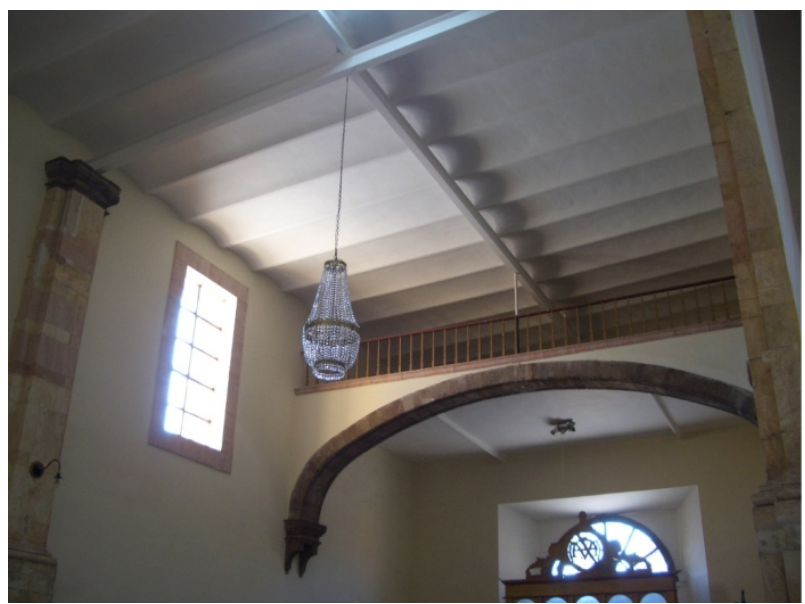

Figura 12. Intervención que no siguió los lineamientos internacionales de conservación 


\section{COMENTARIOS Y RECOMENDACIONES FINALES}

El refuerzo de construcciones históricas tiene como objetivo el corregir las posibles insuficiencias estructurales del edificio o la de mejorar su respuesta estructural. Sin embargo cualquier acción de refuerzo causará, por sí mismo, algunas pérdidas en los valores intrínsecos de la estructura. Por ejemplo, un cambio en los materiales originales y en las características estructurales. Debido a esto, siempre será mejor dar un adecuado y continuo mantenimiento a la estructura, que hacer grandes obras de intervención.

Los criterios actuales para la restauración de estructuras históricas proponen que las intervenciones sean mínimas, no invasoras, reversibles, compatibles y durables. El profesionista encargado de la intervención necesita considerar varias propuestas posibles, que permitan obtener el nivel necesario de seguridad adecuado. Entre estas alternativas, se debe preferir la que cause el menor cambio a la estructura y por ende la que provoque la menor pérdida de los valores intrínsecos.

Tanto el arquitecto como el ingeniero deben entender que cada problema constituye un caso único, por lo que no se puede formular ninguna regla general. Las diferentes técnicas modernas o tradicionales deben ser estudiadas con detalle y se deben analizar siguiendo un criterio de costo - beneficio. Ninguna regla o razonamiento general pueden sustituir la experiencia y el buen juicio del diseñador.

Debido a esto, el ingeniero encargado de proponer una intervención debe ir más allá de los hechos meramente técnicos y debe, forzosamente, involucrarse en otros aspectos que podrían considerarse de otras áreas. Entre los que destacan: historia y arquitectura del edificio a intervenir, documentación del proceso de intervención y salvaguarda de los valores intrínsecos del inmueble histórico. Así mismo, debe estar en continuo contacto y colaboración con los otros profesionistas que integren el proyecto de intervención. Esto dará como resultado una mejor integración del proyecto estructural en el proyecto general de intervención, así como en la salvaguarda de los valores intrínsecos del inmueble.

Esto último se debe a que, para proponer una intervención que se rija por los criterios actuales de conservación, es necesario que se realice un análisis integral del inmueble. Este análisis debe abarcar tres actividades primarias: análisis de las condiciones pasadas, análisis de las condiciones actuales y análisis de las condiciones futuras. Es decir, estas tres actividades se pueden resumir como: conocer para entender, entender para prever y prever para conservar.

El análisis de las condiciones pasadas permite conocer la historia de la edificación a lo largo del tiempo. Permite identificar los valores intrínsecos del inmueble, así como ayuda a entender la condición actual del mismo. Las condiciones presentes permiten, precisamente, saber el grado de afectación del inmueble. Es aquí donde se planea la posible intervención a realizar. Por último, es necesario que se reconozca la importancia de tener un análisis o previsión de las condiciones futuras del inmueble. Esto se debe a que uno de los objetivos de la conservación es la de prever las posibles acciones a futuro, para permitir que el inmueble se mantenga vivo, conserve su identidad original y se evite la pérdida de sus valores intrínsecos. Es decir, que el Patrimonio Arquitectónico se conserve con la dignidad que merece.

\section{AGRADECIMIENTOS}

El primer autor agradece el financiamiento recibido por parte del Instituto de Ingeniería de la UNAM, por medio de su Fondo Interno para Proyectos, mediante el proyecto 1561 "Caracterización dinámica de iglesias coloniales”. Todas las fotografías e ilustraciones de este documento han sido tomadas 
o realizadas por los autores; algunas de las cuales han sido previamente publicadas en otros trabajos de los mismos autores.

\section{REFERENCIAS}

Betti, M y A Vignoli (2008), “Assessment of seismic resistance of a basilica-type church under earthquake loading: Modelling and analysis”, Advances in Engineering Software, Vol. 39, pp. 258-283.

Binda, L, M Luadi y A Saisi (2007), "Non-destructive testing techniques applied for diagnosis investigation: Syracuse Cathedral in Sicily, Italy”, International Journal of Architectural Heritage, Vol. 1, pp. 380-402.

Borri, A, M Corradi y A Vignoli (2002), "New materials for strengthening and seismic upgrading interventions”, Workshop Ariadne 10 New Materials for safeguarding cultural heritage. Disponible en: http://www.itam.cas.cz/ arcchip/ariadne_10.shtml

Bosiljkov, V, M Uranjek, R Zarnic y V Bokan-Bosiljkov (2010), “An integrated diagnostic approach for the assessment of historic masonry structures”, Journal of Cultural Heritage, Vol. 11, pp. 239-249.

Calderini, C (2008), "Use of reinforced concrete in preservation of historic buildings: conceptions and misconceptions in the early 20th century”, International Journal of Architectural Heritage, Vol. 2, pp. 25-59.

Chávez, M, y R Meli (2010). "Ensaye en mesa vibradora de un templo típico colonial: evaluación de dos esquemas de refuerzo”, XVII Congreso Nacional de Ingeniería Estructural, León, Artículo 11-02.

Corradi, M, A Grazini y A Borri (2007), “Confinement of brick masonry columns with CFRP materials”, Composites Science and Technology, Vol. 67, pp. 1772-1783.

EECCP (2006a), "Guidelines for the conservation of historical masonry structures in seismic areas", Improving the Seismic Resistance of Cultural Heritage Buildings. Project deliverable, EECCP-EUIndia Economic Cross Cultural Program. Disponible en: http://www.civil.uminho.pt/eu-india

EECCP (2006b), “Identification of strengthening strategies”, Improving the Seismic Resistance of Cultural Heritage Buildings. Project deliverable, EECCP-EU-India Economic Cross Cultural Program. Disponible en: http://www.civil.uminho.pt/eu-india

Ganniari-Papageorgiou E (2009), “Joining fragmented epistyles using threaded titanium bars: a numerical analysis”, Strain, Vol. 45, No. 5, pp. 445-455.

Gentile, C y N Gallino (2008), “Ambient vibration testing and structural evaluation of an historic suspension footbridge”, Advances in Engineering Software, Vol. 39, pp. 356-366.

ICOMOS (1931), “La Carta de Atenas para la restauración de monumentos históricos”, ICOMOS. Disponible en: http://www.international.icomos.org/centre_documentation/chartes_eng.htm

ICOMOS (1964), “Carta internacional sobre la conservación y la restauración de monumentos y sitios (Carta de Venecia)”, ICOMOS. Disponible en:

http://www.international.icomos.org/centre_documentation/chartes_eng.htm

ICOMOS (1996), "Principles for the recording of monuments, groups of buildings and sites", ICOMOS. Disponible en: http://www.international.icomos.org/centre_documentation/chartes_eng.htm

ICOMOS (2003a), "Principios para el análisis, conservación y restauración estructural del patrimonio arquitectónico”, ICOMOS. Disponible en:

http://www.international.icomos.org/centre_documentation/chartes_eng.htm 
ICOMOS (2003b), "Recomendaciones para el análisis, conservación y restauración estructural del patrimonio arquitectónico”, ICOMOS. Disponible en:

http://www.international.icomos.org/centre documentation/chartes eng.htm

Liu, Q, Y Liu, K Zeng, F Yang, H Zhu y Q Liu (2011), “Advanced design of Chinese traditional materials for the conservation of historic buildings”, Journal of Archaeological Science, DOI:10.1016/j.jas.2011.03.036

Lourenço, P B (2006), "Recommendations for restoration of ancient buildings and the survival of a masonry chimney”, Construction and Building Materials, Vol. 20, pp. 239-251.

Lourenço, P B, P Roca, F Peña, D V Oliveira y F Casarin (2007), "Repair and strengthening techniques for ancient masonry constructions in seismic zones", Fifth International Conference on Seismology and Earthquake Engineering, Tehran.

Lourenço, P B, F Peña y M Amado (2011), “A document management system for the conservation of cultural heritage buildings”, International Journal of Architectural Heritage, Vol. 5, pp. 101-121.

Meli, R (1998), “Ingeniería estructural de los edificios históricos”, Fundación ICA, México, 220 p.

Meli, R y A R Sánchez Ramírez (2007), “Criteria and experiences on structural rehabilitation of stone masonry buildings in Mexico city”, International Journal of Architectural Heritage, No. 1, pp. 328.

Orduña, A, G Roeder y F Peña (2007), “Evaluación sísmica de construcciones históricas de mampostería: comparación de tres modelos de análisis”, Revista de Ingeniería Sísmica, No. 77, pp. 71-88.

Paret, T F, S A Freeman, G R Searer, M Hachem y U M Gilmartin (2008), "Using traditional and innovative approaches in the seismic evaluation and strengthening of a historic unreinforced masonry synagogue”, Engineering Structures, Vol. 30, pp. 2114-2126.

Penelis, G (2002), "Structural restoration of historical buildings in seismic areas", Progress in Structural Engineering and Materials, Vol. 4, pp. 64-73.

Peña, F (2010), “Estrategias para el modelado y el análisis sísmico de estructuras históricas”, Revista de Ingeniería Sísmica, No. 83, pp. 43-63.

Peña, F, D Rivera y C Arce León (2010). "La conservación del patrimonio arquitectónico mediante una visión multidisciplinaria: el papel de la ingeniería”, XVII Congreso Nacional de Ingeniería Estructural, León, Artículo 11-06.

Quagliarini, E, M D’Orazio y A Stazi (2006), "Rehabilitation and consolidation of high-value 'camorcana' vaults with FRP”, Journal of Cultural Heritage, Vol. 7, pp. 13-22.

Valluzzi, M R (2007), “On the vulnerability of historical masonry structures: analysis and mitigation”, Materials and Structures, Vol. 40, pp. 723-743.

Zegarra, L, A San Bartolomé, D Quiun y A Giesecke (1997), "Manual técnico para el reforzamiento de las viviendas de adobe existentes en la costa y sierra", Proyecto GTZ-CERESIS-PUCP, Lima. Disponible en: http://www.ceresis.org/proyect/madobe/maual.htm 